\title{
Juntos no Controle do Aedes aegypti: EducAÇãO em Saúde
}

\author{
Roberta Mendes Von Randow, Juliana Santiago da Silva, Jeane de Fátima Cunha Brandão, Isabella \\ Boechat Carvalho Oliveira, Jocimar Kenede Oliveira Barbara, Nathália Gonzaga Nascimento
}

\begin{abstract}
Resumo
O Aedes aegypti é um mosquito antropofílico, isto é, ele vive perto do homem. Por isso, sua presença é mais comum em áreas urbanas e a infestação é mais intensa em regiões com alta densidade populacional e, principalmente, de desocupação desordenada, onde as fêmeas têm mais oportunidades para alimentação e dispõem de mais locais para desovar. A infestação por Aedes aegypti é sempre mais intensa no verão, em função da elevação da temperatura e da intensificação de chuvas, fatores que propiciam a reprodução do mosquito. O Aedes aegypti é responsável pela transmissão da dengue, chikungunya e vírus zika, que são atualmente grave problema de saúde pública em todo país. Desenvolver estratégia de prevenção à saúde relacionada ao controle do vetor Aedes aegypti. Trata-se de um projeto de extensão desenvolvido desde fevereiro de 2016, por professores e acadêmicos dos cursos de medicina, enfermagem e gestão ambiental de uma instituição de ensino superior. São instituições parceiras: Secretaria Municipal de Saúde de Manhuaçu por meio do setor de Vigilância em Saúde, Vigilância Ambiental. As ações foram desenvolvidas a partir das seguintes etapas: 1) Vistoria dos Campus da FACIG e orientação de funcionários; 2) Orientação e sensibilização de acadêmicos da Instituição para eliminação de possíveis criadouros e/ou focos do mosquito em suas residências e entrega de panfletos informativos; 3) Ação de mobilização "Dia D contra o Aedes aegypti". Durante 06 (seis) meses de realização do projeto todas as ações previstas foram desenvolvidas. A primeira ação foi desenvolvida no Campus Ilha de Excelência e no Campus Alfa Sul. Teve como objetivo a detecção e eliminação de possíveis criadouros do mosquito. A ação foi acompanhada pelos agentes de endemias responsáveis pelos bairros de ambos os Campus, em cada Campus a vistoria foi acompanhada por funcionário que tornou-se responsável pela "vistoria semanal contra o Aedes" seguindo orientações do Ministério da Saúde. Para o desenvolvimento da segunda ação os acadêmicos visitaram as salas dos demais cursos da Instituição, informando e sensibilizando todos acadêmicos a apoiarem a ação de combate ao mosquito, foram entregues panfletos educativos. A terceira ação foi desenvolvida juntamente com as equipes de Saúde da Família, equipes do Núcleo de Atenção a Saúde da Família (NASF), equipe vigilância ambiental, agentes de endemias, além de demais instituições públicas e privadas do município. Os acadêmicos esclareceram a população sobre como evitar a proliferação do mosquito, sinais e sintomas da dengue, chikungunya e zika. A mobilização objetivou também chamar a atenção da população nas ruas da cidade em relação à necessidade de cuidados em casa para a eliminação de focos do mosquito Aedes aegypti. Acreditase que para controlar a situação atual, é preciso desenvolver medidas permanentes para o controle do mosquito, durante todo o ano, a partir de ações preventivas que objetivem a eliminação de focos do vetor. Cabe ressaltar que a educação em saúde torna-se uma estratégia relevante para sensibilização da população, considerando que as ações de prevenção dependem diretamente do empenho de toda a população.
\end{abstract}

Descritores: Prevenção; Saúde coletiva; Aedes aegypti. 